\title{
A CADAVERIC STUDY OF VARIATIONS IN ORIGIN AND BRANCHING OF RENAL ARTERIES
}

\author{
Swapna Thampi ${ }^{1}$, Renuka Krishnapillai ${ }^{2}$
}

${ }^{1}$ Assistant Professor, Department of Anatomy, Government Medical College, TVPM.

2 Professor and HOD, Department of Anatomy, Government Medical College, TVPM.

ABSTRACT

\section{BACKGROUND}

Mostly kidneys are supplied by single renal arteries, which arise from the aorta and enter the kidney through the hilum to divide into segmental branches. This study aims to determine the various branching pattern of segmental branches of single renal artery.

\section{MATERIALS AND METHODS}

This descriptive study was done by obtaining forty eight formalin fixed cadavers from the Department of Anatomy, Medical College, Kottayam.

\section{RESULTS}

Single renal artery originating from the aorta was seen in 85.18\%; varied segmental pattern was obtained.

\section{CONCLUSION}

Awareness of variations in branching pattern of renal arteries is of paramount importance for various surgical, urological and angiographic interventions.

\section{KEYWORDS}

Single Renal Artery, Aortic Origin, Segmental Branches.

HOW TO CITE THIS ARTICLE: Thampi S, Krishnapillai R. A cadaveric study of variations in origin and branching of renal arteries. J. Evolution Med. Dent. Sci. 2017;6(52):3943-3946, DOI: 10.14260/Jemds/2017/853

\begin{abstract}
BACKGROUND
Renal arteries branch laterally from the aorta just below the origin of superior mesenteric artery. The right renal artery is longer and higher passing posterior to Inferior Vena Cava (IVC). It may be crossed anteriorly by inferior mesenteric vein. A single renal artery to each kidney is present in $70 \%$ individuals. Artery varies in their level of origin and their calibre. Near the hilum each artery divides into anterior and posterior division, which in turn divides into segmental arteries supplying renal vascular segments. Anterior division usually gives apical, upper, middle and lower segmental artery, while posterior division continues as posterior segmental artery. There can be variations in segmental distribution of anterior and posterior divisions. This study aims to find varying origin, relations of single renal arteries, other branches arising from them and their segmental distribution. Prehilar origin and absence of segmental branches were also noted. Knowledge of renal segmental pattern is of importance to avoid complications during segmental resections, renal transplantation, urologic procedures, etc.
\end{abstract}

\section{MATERIALS AND METHODS}

The formalin fixed 48 cadavers from the Department of Anatomy, Government Medical College, Kottayam were

Financial or Other, Competing Interest: None.

Submission 24-05-2017, Peer Review 16-06-2017,

Acceptance 23-06-2017, Published 29-06-2017.

Corresponding Author:

Dr. Renuka Krishnapillai,

Rasmi, TC-41/1689,

Manacaud,

TVPM-695009.

E-mail:drrenukak@rediffmail.com

DOI: $10.14260 /$ jemds $/ 2017 / 853$

\section{(c) $(1)(5)$}

studied. Along with routine dissection for undergraduates, after opening the abdomen other viscera were removed and relations of hilar structures were noted. Sixty nine kidneys were found to have single renal arteries, all arising from the aorta. Level of origin was noted and each vessel was traced to the kidneys. Relations with IVC, ureter and gonadal vessels was specifically looked for. Then kidneys were removed after dividing ureter and vessels. Each renal artery was traced dissecting and micro dissecting the kidney, and its branching pattern was studied.

\section{RESULTS}

We observed single renal arteries in $85.18 \%$ (69 kidneys) cases. The arteries originated from the aorta and had different levels of origin as shown in Table 1.

\section{Table 1}

Normal arrangement of the hilar structures with vein anterior, renal pelvis posterior and artery in between was observed in $85.5 \%$ cases. In $7.2 \%$ cases the renal artery curved around the upper border of renal vein, divide into segmental branches which entered from anterior aspect. In $1.45 \%$ a posterior lobar vein was seen posterior to the pelvis joining the main renal vein towards the inferior vena cava. The renal arteries divide normally into anterior and posterior division at varying distance from the aorta. The main stem towards hilum divides into anterior and posterior divisions. Anterior division usually gives Apical, Upper, Middle and Lower Segmental Artery (ASA, USA, MSA and LSA), while posterior division continues as Posterior Segmental Artery (PSA). Variation was seen in 2 kidneys where anterior division supplied middle and lower segments, while posterior gave upper and posterior segments (Fig. 1). Occasionally, the segmental arteries may be absent. In this study, upper segmental was absent in 6 kidneys, posterior segmental in 6 kidneys and middle segmental in 1 (Fig. 2). In one kidney, 
both upper and lower segmental was absent. The apical and lower segmental artery supplies both anterior and posterior planes. At times the apical and lower segmental vessels arise quite independent from the remaining segmental vessels, termed as prehilar segmental branching which can be mistaken as double renal arteries. In this study, the normal hilar segmental branching was found in $86.95 \%$, while $13.4 \%$ showed prehilar branching. Prehilar origin was shown by upper segmental branch in two kidneys (Fig. 3) and lower segmental branch in seven kidneys. Extrahilar entry was made by ASA in $7.2 \%$ cases (Fig. 4 ) by USA in $2.9 \%$, by LSA in $10.14 \%$ and by accessory polar artery in $20.29 \%$.

Apical Segmental Artery (ASA) can originate in Four Ways

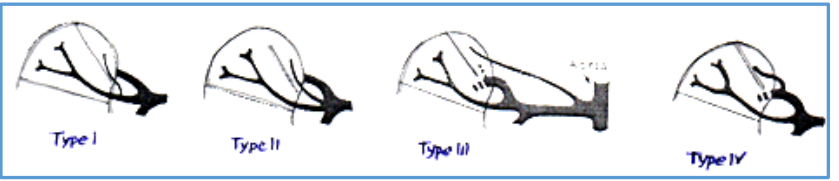

- Type I- Arising from short trunk of anterior division or from upper segmental artery.

- Type II- Arising from junction of anterior and posterior division with the main stem (Fig. 5).

- Type III- Arising from main renal artery close to aorta and makes extrahilar entry.

- Type IV-Arising from posterior division.

Types of apical segmental artery is shown in Table 2 Apical segmental arteries made extrahilar entry in $7.2 \%$ cases.

Accessory Apical Segmental Arteries (ASA) usually arise from posterior segmental artery. In this study, such vessels were seen in 14 kidneys, all arising from posterior segmental except one from middle segmental artery.

The anterior division further divides into upper, middle and lower segmental branches which can be grouped as follows.

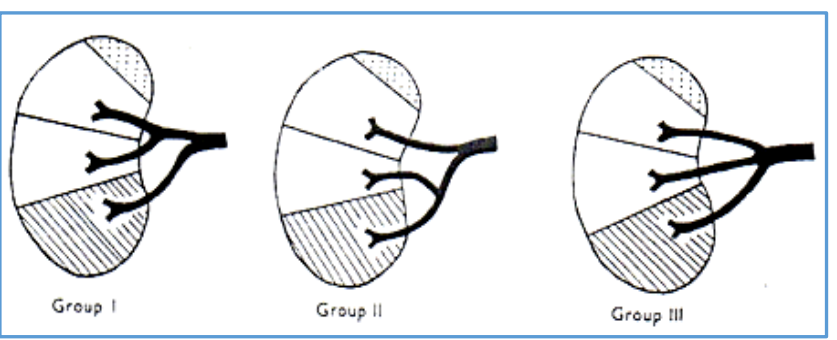

- Group I- Lower segmental branch arise first, the other two have a common origin.

- Group II- Lower segmental branch arise with upper segmental artery. Middle segmental arises from side of lower segmental artery (Fig. 6).

- Group III- All the three have a common origin.

The percentage of groups of anterior division in this study is shown in Table 3 .

\begin{tabular}{|c|c|c|c|c|}
\hline & T12-L2 & L1 & L1-L2 & L3 \\
\hline Right renal artery & 1 & 29 & 3 & 2 \\
\hline Left renal artery & 0 & 1 & 25 & 8 \\
\hline Table 1. The different Vertebral Levels of Origin of Renal \\
Arteries is shown Below \\
\hline
\end{tabular}

\begin{tabular}{|c|c|}
\hline Type of Apical Segmental Artery & Percentage \\
\hline Type I & $43.47 \%$ \\
\hline Type II & $13.04 \%$ \\
\hline Type III & $10.14 \%$ \\
\hline Type IV & $21.73 \%$ \\
\hline $\begin{array}{r}\text { Table 2. Shows the Percentage of Type of Apical } \\
\text { Segmental Artery according to Origin }\end{array}$ \\
\hline
\end{tabular}

\begin{tabular}{|c|c|}
\hline $\begin{array}{c}\text { Groups according to Branching of } \\
\text { Anterior Division }\end{array}$ & Percentage \\
\hline Group I & $31.88 \%$ \\
\hline Group II & $30.43 \%$ \\
\hline Group III & $8.69 \%$ \\
\hline Table 3. Shows Percentage of Groups of Anterior Division \\
\hline
\end{tabular}

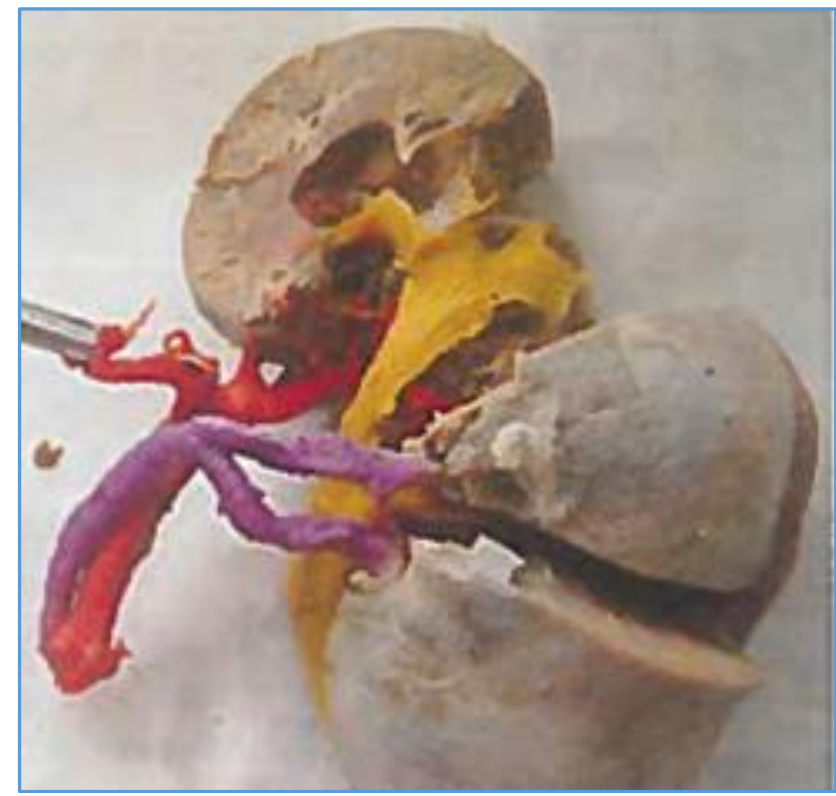

Figure 1. Anterior Division (Purple) gives Middle and Lower Segmental Artery, while Posterior Division (Red) gives Upper and Posterior Segmental Branch

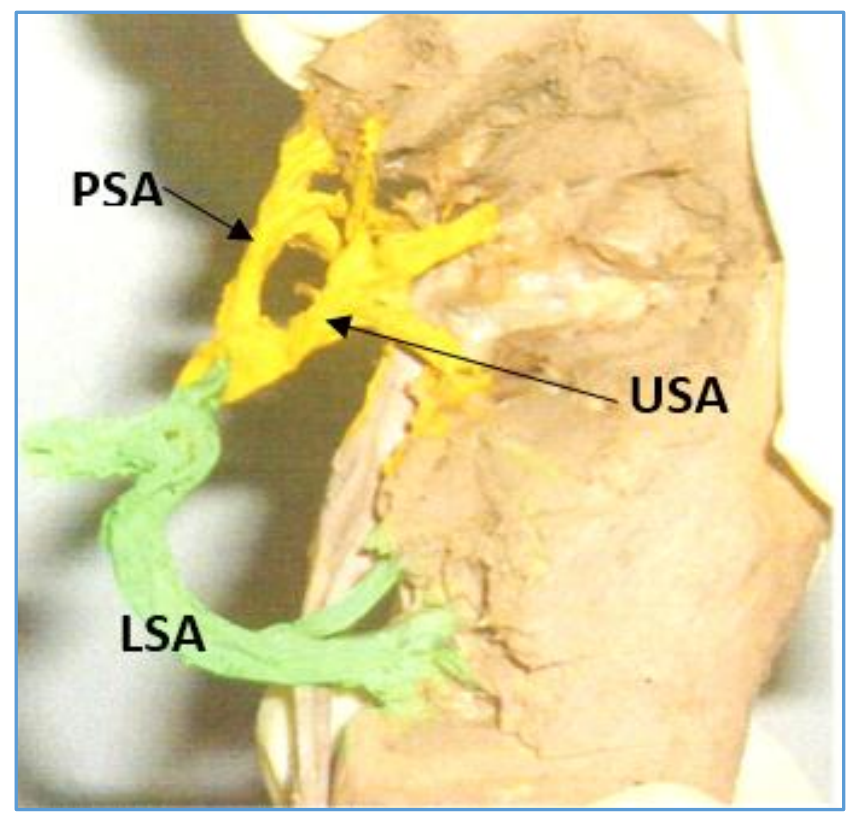

Figure 2. Middle Segmental Artery is Absent. Upper Segmental (USA), Middle Segmental (MSA) and Posterior Segmental Artery (PSA) Seen 


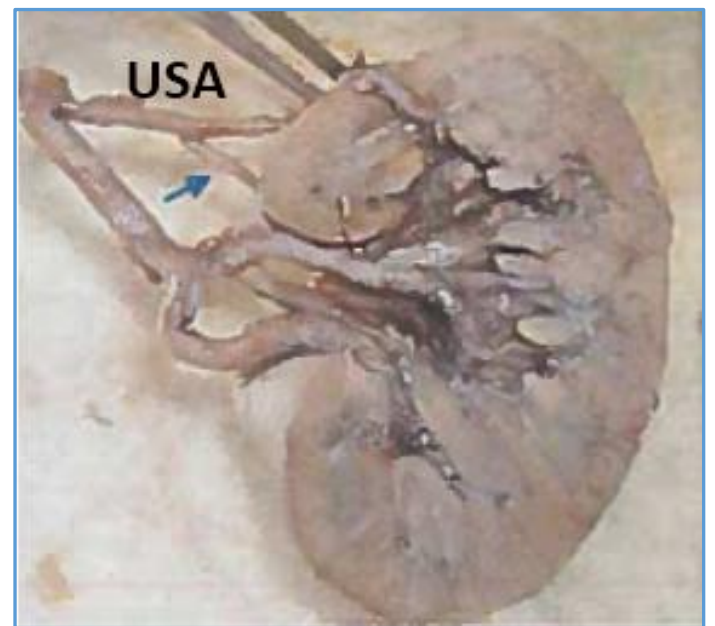

Figure 3. Prehilar Origin of Upper Segmental Artery which also gives a Polar Branch (Blue Arrow), and Main Renal Artery Trifurcates into Middle, Lower and Posterior Segmental Branch

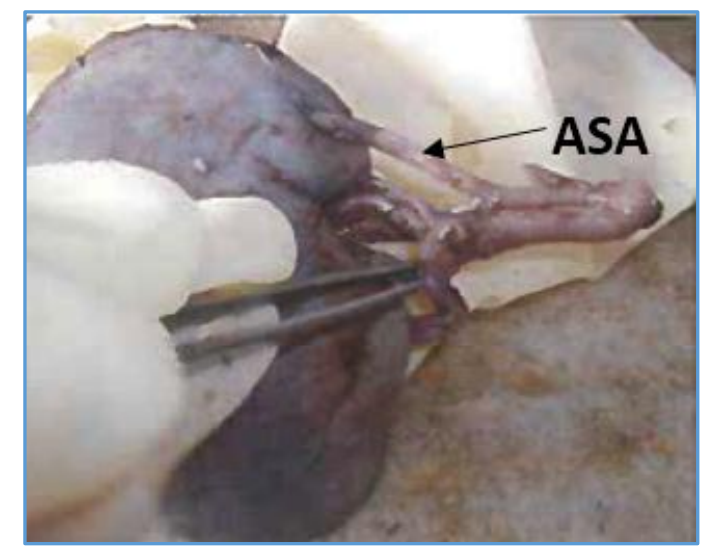

Figure 4. Extrahilar Entry of Apical Segmental Artery (ASA)

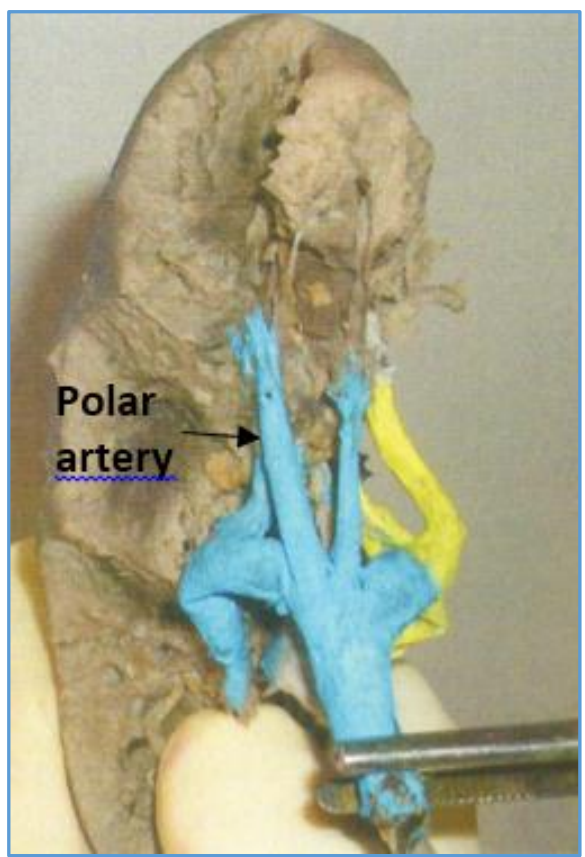

Figure 5. Two Polar Artery arising from Junction of Anterior and Posterior Division

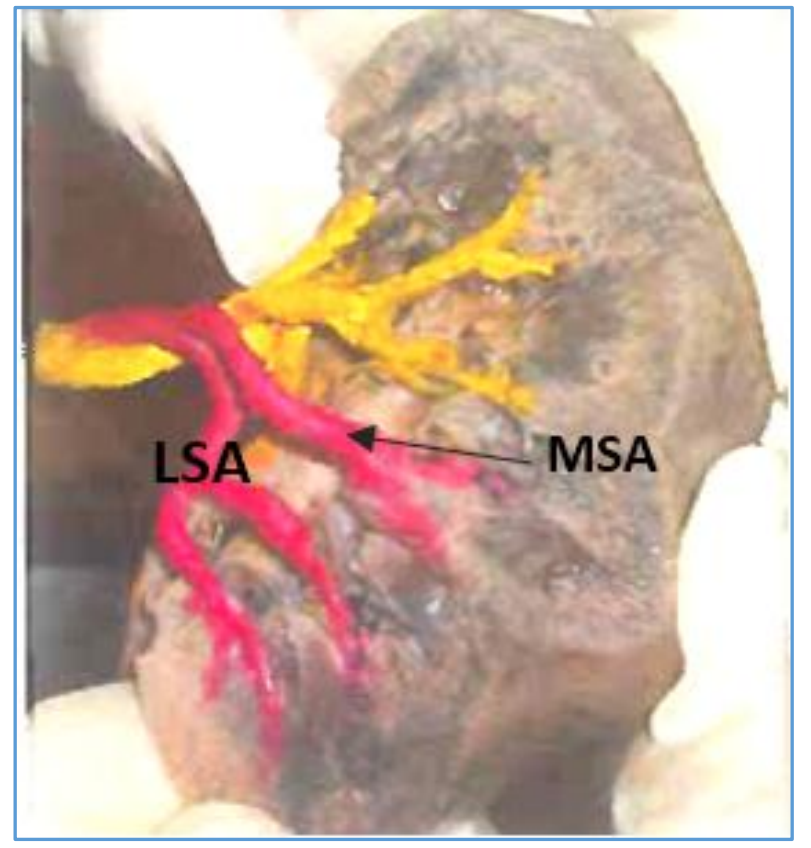

Figure 6. Middle Segmental Artery (MSA) arising from Lower Segmental Branch (LSA)

\section{DISCUSSION}

Renal vascular segmentation was originally recognised by John Hunter ${ }^{1}$ and Brodel M. ${ }^{2}$ In 1954, Graves ${ }^{3}$ described the segmental pattern of intrarenal arterial distribution and its variation. He divided the renal parenchyma into five segments. The arterial pattern was reviewed by Fourman and Moffat ${ }^{4}$ in 1971 and was applied to segmental resection of kidneys.

Kher ${ }^{5}$ observed that anterior division gives origin to apical segmental artery first and then to upper, middle and lower segmental arteries. Verma ${ }^{6}$ studied the intrarenal branching pattern of renal artery and observed more variations than Graves. Saxena ${ }^{7}$ has done the radiographic study and described four to five arterial segments according to variations in branching pattern of renal artery. The area of kidney tissue, which is supplied by a segmental artery is known as renal segment. The segmental arteries are supposed to be the end arteries, Hunter and have also been observed in the present study. Sampio FJB ${ }^{8}$ et al revealed that serious complication of endoscopic intrarenal operation is bleeding from an injured vessel. To decrease that surgeons must know and recall spatial position of intrarenal vessel.

The new techniques which are employed in renal surgery mainly depend upon the segmental resection, namely the wedge-type resections, if the disease affects the upper or the lower segments. The lack of arterial anastomosis in the neighbouring segments will affect only the affected segment and it will neither produce ischaemia nor interfere with the blood supply of the neighbouring segments. This lack of the arterial anastomosis will render the technique of the resection easier, since the field of operation will be relatively bloodless following the ligation of the segmental artery which supplies the area of the operation. Neeraja Rani ${ }^{9}$ et al in an angiographic study reports as in majority of the cases, origin of the segmental arteries are easily seen in the hilum and they are often at the points which are near to the aorta. This is of 
practical value, since the segmental resection is best carried out from the hilum towards the periphery.

Pozniak $\mathrm{M}^{10}$ et al observed that the main renal artery divides within $1.5 \mathrm{~cm}$ of renal ostium in abdominal aorta, it is called early branching and can be mistaken as double renal artery. Daescu ${ }^{11}$ et al in his study on branching pattern observed prehilar branching of renal artery in $81.67 \%$, hilar in $10 \%$ and intrasinusal in $8.33 \%$. In $53 \%$ cases the segmental arteries arouse independently from renal artery, while in $47 \%$ cases they come from common trunks. In this study, prehilar branching was seen in $13.4 \%$ cases. As per Kawamoto $^{12}$ et al, it is essential to identify any prehilar branching since surgeons require at least $2 \mathrm{~cm}$ length of renal artery to guarantee satisfactory control and anastomosis.

Seema Rani ${ }^{13}$ et al observed 15\% polar artery arising from the main renal artery and entered the parenchyma directly. In a study by Gyan Prakash ${ }^{14}$ et al, the USA was arising from ASA in 20\%, MSA in 28\% and PSA in $10 \%$. In this study USA and MSA arising from a common trunk in $31.88 \%$, USA and LSA arising from a common trunk in $30.43 \%$ in which LSA also gives MSA and in $8.69 \%$ cases the anterior division after giving polar artery trifurcated into USA, MSA and LSA. Longia ${ }^{15}$ et al in a study of corrosion casts reported $48 \%$ kidneys with 4 renal segmental arteries probably due to fusion of ASA and USA or MSA and LSA or due to absence of ASA. In this study, $15.26 \%$ kidneys has only 4 segmental arteries and in $1.2 \%$ cases had only 3 segmental arteries.

\section{CONCLUSION}

In this study, single renal arteries was seen in $85.18 \%$ cases. Upper segmental artery was absent in 6 kidneys, posterior segmental in 6 kidneys and middle segmental in 1; prehilar branching was observed in $13.4 \%$. In 2 kidneys anterior division supplied middle and lower segments, while posterior gave upper and posterior segments. Variations in origin of various segmental branches was observed. Anatomical knowledge of vasculature of human kidney and its segmental distribution plays an important role in partial resection and transplantation procedures as controlling the haemorrhage is one of the technical skills, otherwise uncontrolled bleeding could even necessitate nephrectomy. Partial or segmental resection of the kidneys will help in the further development of different techniques for the removal of calculi or any affected part of kidneys. This will also help in partial renal transplantation surgeries with end-to-end anastomosis of the resected part of the kidney. There is lot of variation in their course and exact point-of-origin of the arterial segments of the kidney. Moreover, it is of valuable contribution of development of new and different techniques for removal of renal calculi like percutaneous nephrolithotomy. Further, open surgical nephrectomy can be replaced by laparoscopic nephrectomy and easy removal of renal tumours. Knowledge of the variations of renal vascular anatomy has importance in exploration and treatment of renal trauma, renal transplantation, renal artery embolisation, surgery for abdominal aortic aneurysm and conservative or radical renal surgery.

\section{REFERENCES}

[1] Hunter J. Vasculature of the body. Br J Surg 1794;38:18.

[2] Brodel M. The intrinsic blood vessels of the kidney and their significance in nephrotomy. Bull John Hopkin's Hosp 1901;12:10.

[3] Graves FT. The anatomy of intrarenal arteries and its application to segmental resection of the kidneys. Br J Surg 1952;42:132-40.

[4] Fourman J, Moffat DB. The blood vessels of the Kidney. Oxford: Blackwell 1971.

[5] Kher GA, Bhargava IFS, Makhni. Intrarenal branching of the renal artery. Ind J Surg 1960;22:563-79.

[6] Verma M, Chaturvedin RP, Pathak RK. Anatomy of the renal vascular segments. J Anat Soc 1961;10:12-14.

[7] Saxena SK, Dikshit CS, Saxena HN. A radiographic study of intrarenal arteries. Mediscope 1973;16(1):19.

[8] Sampaio FJB, Aragao AHM. Anatomical relationship between the intrarenal arteries and the kidney collecting system. The Journal of Urology 1990;143(4):679-81.

[9] Rani N, Singh S, Dhar P, et al. Surgical importance of arterial segments of human kidneys: an angiography and corrosion cast study. Journal of Clinical and Diagnostic Research 2014;8(3):1-3.

[10] Pozniak MA, Balison DJ, Lee FT, et al. CT angiography of potential renal transplant donors. Radiographics 1998;18(3):565-87.

[11] Daescu E, Zahoi DE, Motoc A, et al. Morphological variability of the renal artery branching pattern: a brief review and an anatomical study. Rom J Morphol Embryol 2012;53(2):287-91.

[12] Kawamoto S, Montgomery RA, Lawler LP, et al. Multidetector row CT evaluation of living renal donors prior to laparoscopic nephrectomy. Radiographics 2004;24(2):453-66.

[13] Khajuria SR, Saini H, Agarwal RK, et al. Variations in renal artery with presence of upper polar segmental artery. Internal Journal of Basic and Applied Medical Sciences 2015;5(2):128-31.

[14] Mishra GP, Bhatnagar S, Singh B. Anatomical variations of upper segmental renal artery and clinical significance. JCDR 2015;9(8):AC01-AC3.

[15] Longia GS, Kumar V, Gupta CD. Intrarenal arterial pattern of human kidneys-corrosion cast study. Anat Anz 1984;155(1-5):183-94. 